\title{
Conflictos entre linajes y comunidades de vecinos en el norte de Navarra en el siglo XVII
}

\author{
Fernando Mikelarena Peña *
}

En el período que cubre los siglos XVI y XVII, los valles montañeses del norte de Navarra atestiguaron una agudizada conflictividad social entre los linajes o "parientes mayores" y las comunidades de vecinos de cada localidad o valle por la cual éstas discutieron los privilegios de los primeros en un intento - conseguido casi siempre - de cercenar cualquier proceso tendente a la señorialización. Los rasgos tipológicos de esa conflictividad muestran la presencia de una triplicidad de variantes según el ámbito concreto de lo dirimido en cada pleito: conflictos por preferencias en las iglesias, conflictos por diezmos y construcción de molinos y conflictos por alcaldías perpetuas y concesiones jurisdiccionales. No obstante, la circunstancia de que en la mayoría de los casos que se describen a continuación consten dos o tres de esas variantes prueba el carácter para nada anecdótico de esas diferencias.

\section{LOS CONFLICTOS ENTRE LOS ALZATE Y LA VILLA DE VERA}

Aparte de por su intensidad, las diferencias mantenidas entre la villa de Vera y el linaje de Alzate poseen la particularidad de su prolongación

* Becario del Departamento de Historia Medieval y Moderna. 
en los intentos de dos vecinos enriquecidos por asumir los privilegios disfrutados por el linaje.

Los primeros procesos fueron con motivo del derecho de presentación de rector que poseía Alzate por su patronato. Así, en 1604 los vecinos solicitaban ante el tribunal eclesiástico que no tuviera efecto la presentación de Lorenzo de Hualde a causa de ser este francés ${ }^{1}$. Aunque Hualde argumentaba que había nacido y había sido bautizado en la propia localidad ${ }^{2}$, los vecinos recordaban que no cumplía los requisitos estipulados al ser sus padres de otro país ${ }^{3}$. Por otra parte, las acusaciones en contra de Hualde de comportamiento no muy ético ${ }^{4}$, se repetían, junto con otras referidas a su carácter de usurero, en otro proceso de $1605^{5}$. En este contexto, resulta explicable la actitud de Hualde, ciertamente animado por Alzate, en to relativo al ambiente de paroxismo colectivo que vivió el pueblo, junto con el resto de la zona, en 1609-1611 ${ }^{\circ}$. No obstante, los enfrentamientos entre el linaje y los vecinos no culminaron ahí. En 1638, como una acción más de la guerra entre españoles y franceses, Vera fue incendiada "haviendo entrado en ella para este efecto quatro mill infantes y quinientos cavallos conducidos por D. Salvador de Alçate y Urtubia Vizconde de Urtubia cavallero frances y Dueño del Palacio de Alçate que es sito en la dha. Villa de Vera y como tal Patrono de la Retoria" ${ }^{\text {? }}$.

A partir de 1665 no fue el representante del linaje quien pleiteó con los vecinos, sino un militar enriquecido, Miguel de Yriarte y Taberna $^{8}$, que había comprado en carácter de carta de gracia ${ }^{9}$ los bienes pertenecientes al Palacio de Alzate y, como tal dueño, trató de hacer valer los privilegios del linaje. De esta forma, un auto municipal informaba que el

1 Archivo Diocesano de Pamplona (en adelante ADP), Ibáñez, 425-1, fol. 5-5v.

2 lbidem, fol. 15.

3 Ibidem, fol. 39.

4 lbidem, fol. 71.

5 ADP, Garro, $445-4$, fol. 2 y 30v-31v.

- Según Caro Baroja, en el proceso de brujería de esos años, más responsabilidad que al inquisidor Valle Alvarado "parece que les cupo al rector de Vera, licenciado Hualde, y al antiguo señor de Alzate que vivía en el château d'Urtubie y que fue el que, en el Labourd, provocó la persecución llevada a cabo por Pierre de Lancre" (Inquisición, brujería y criptojudaismo, Barcelona 1970, p. 196).

7 Archivo Municipal de Vera, legajo separado, n. ${ }^{\circ} 5$.

8 En el apeo fogueral de 1678 consta, dueño de seis casas, como el mayor propietario en cuanto a número de casas.

${ }_{9}$ La venta en carta de gracia o en pacto de retro era una modalidad de enajenación por la cual el vendedor conservaba el derecho de rescatar el bien inmueble vendido. 
ayuntamiento había ordenado cerrar las puertas de la iglesia y colocado guardas ante ellas con el fin de que Yriarte «no entre en posesion de lo que al dicho palacio le perteneze» ${ }^{10}$. Por otro lado, ese mismo año se iniciaba un proceso ante el Real Consejo entre las mismas partes porque la villa de Vera quería construir dos molinos sobre el mismo río en que Alzate antes e Yriarte ahora poseía otros dos molinos. Según el procurador de Yriarte, la villa no tenía "necesidad alguna" de esos molinos y sólo deseaba molestar a Alzate y a Yriarte "con la mala voluntad que les tienen por las prerrogatibas y precedencias calidades y antigüedad del dho. Palacio de Alçate» " ${ }^{11}$. Por su parte, los argumentos de la villa giraban en torno a varios puntos: la insuficiencia de los cuatro molinos existentes, dos municipales y dos del palacio, para moler todo el grano ${ }^{12}$; el seguro incremento de las debilitadas rentas municipales ${ }^{13}$; el nulo perjuicio que se seguía para los molinos de la parte contraria de que se construyeran dos molinos sobre el mismo río ya que anteriormente sobre él habían funcionado cuatro ferrerias ${ }^{14}$; y, por último, quizás el más importante, la imposibilidad de Yriarte, como comprador y heredero de los bienes y derechos vinculados al palacio de Alzate, de obstaculizar cualquier obra, en cuanto que, según un testigo, en 1617 el dueño del palacio no había interpuesto ninguna traba a la construcción de un molino municipal sobre el mismo río ${ }^{15}$. Como expresión, en fin, del grado de enfrentamiento a que se había llegado, un testigo presentado por Yriarte -quien ganaría finalmente el pleito- acusaba a los de la villa de prohibir bajo multas y decomisos a vecinos moler el grano en los molinos de Alzate ${ }^{16}$.

También en 1665 arrancó un extenso pleito sobre preeminencias en la parroquia de Vera en el que en principio litigaban doce particulares - entre ellos Yriarte y Taberna-- contra un tal Pedro de Arosemena y

10 Archivo Notarial de Vera (en adelante ANV), Leg. 11, 1672 (1665), doc. 9. En el mismo documento, Yriarte prometía no sentarse en el asiento del palacio sin antes avisar al alcalde y regidores.

11 "Proceso del Vizconde de Urtubia y consortes contra la villa de Bera sobre Ynivi. cion de nueva obra". Archivo General de Navarra (en adelante AGN), Procesos, Solano, Sentenciados, 1667, fajo 1, carp. 1, fol. $8 \mathrm{v}$.

12 Ibidem, fol. 11.

13 Ibidem, fol. $11 \mathrm{v}$

14 lbidem, fol. 12.

15 lbidem, fol. $75 \mathrm{v}$. Sin embargo, testigos presentados por la parte contraria aducian lo contrario. Así, en el fol. 26, un tal Domingo de Garciazuria declaraba que el municipio fuvo que pagar a Urtubia 200 ducados, información ésta ratificada por otros.

16 Ibidem, fol. $47 \mathrm{~V}$. 
Garmendia y un tal Pedro de Arosemena Alias Elzaurdia. Según los testigos presentados por los doce quejantes, el alcalde ocupaba «el primero y mejor lugar y asiento de los escaños", yendo a continuación el dueño de Garmendia mayor y luego los doce quejantes. Además, en las procesiones y entierros los quejantes habian permitido "por Urbanidad y cortesia» ir delante a los "Ancianos hombres de buen Arte y porte y que an ocupado los oficios de Alcaldes y regidores», así como a los familiares de los difuntos ${ }^{17}$. Por su parte, la información obtenida a partir de los testigos contrarios coincidía en que no había ningún banco «mas adelante que otro" y que por tanto ninguno de los ocho bancos existentes era "de mayor onor que los demas". Incluso, ni el alcalde tenía asiento separado sentándose "en la punta de qualquiera de los dichos vancos, y así son todas las puntas de ellos de los dichos Alcaldes para sentarse en los que ellos escoxieren». Asimismo, aunque se admitía con algunos matices que a la hora de ofrecer los quejantes tenian, después del alcalde y del dueño de la casa de Garmendia mayor, preeminencias respecto de los demás, lo que se rechazaba de plano era el intento de los quejantes de preferir a los ancianos en las procesiones ${ }^{18}$. Así las cosas en la última Pascua se habían producido altercados y empujones entre los quejantes y los dos Arosemenas ${ }^{19}$. Significativamente, un testigo narraba el siguiente comportamiento de Yriarte y Taberna: conminado por dos vecinos, uno de ellos un tal Juan de Yturria, a que fuera en una procesión tras los ancianos y las personas que habian ocupado cargos de república, Yriarte «les dixo que aquel pueblo no hera de ellos, y le respondieron que era de los ancianos y no de el dicho yriarte, y que el entonces con mucha colera le travo de la capa al dicho yturria y se la Arroxo al suelo dentro en la yglesia (...) y dice el 1 (testigo) que escandaliço la Jente de la Va. el dicho yriarte, y que ablando con el tercero y con el dicho yturria les dixo conmigo quereis ser yguales?" (subrayado mío) ${ }^{20}$.

El 1 de julio de 1666 se falló la primera sentencia de las tres que conocería este pleito. Por ella se reconocía el derecho de los quejantes a sentarse en el banco ya mencionado con «prelación a los acusados y demas Vezinos», pero después del alcalde y del dueño de Garmendia

17 «Proceso de la villa de Bera y Consortes contra Miguel de Yriarte y Conses. sobre preferencia en la Yglesia». AGN, Procesos, Solano, Sentenciados, 1773, fajo 3, carp. 4, fol. $21-21 \mathrm{v}$.

${ }_{18}$ Ibidem, fol. $46-47$.

19 Ibidem, fol. $22-23$ y $47-48 \mathrm{v}$.

20 Ibidem, fol. 91v-92. 
mayor, así como el de preferir en el ofrecer, tomar la paz e ir en procesiones, ésto último sin perjuicio de los ancianos y de los que habian ocupado cargos de república ${ }^{21}$.

El contenido de esa sentencia fue prontamente recurrido por la villa y el conjunto de los vecinos por "el agravio que se les hacia» en cuanto que la sentencia concernía a todos y todos tenían "sus Raçones para no dar lugar a ser Preferidos» e «ynteres de que no se de lugar a que se hagan novedades ni yntroduzcan Precedencias ni Preheminencias por Vezos. Particulares» ${ }^{22}$. La pretensión de la villa era la anulación de la sentencia ya que en su argumentación los ex-cargohabientes siempre habían ido los primeros en ofertorios y procesiones y los regidores debian ir los primeros después del alcalde tanto en los actos de la iglesia como en las procesiones ${ }^{23}$.

En esta parte del proceso, la discusión se centró en la posición preeminente del alcalde y de los regidores en relación con el resto de la vecindad. Por un lado, los quejantes - a los que se sumaba ahora el dueño de Garmendia mayor que disfrutaba de un fuero especial- volvian a declarar que los actos eclesiales debía encabezarlos el alcalde, seguido del dueño de Garmendia mayor y de los quejantes, careciendo los regidores de cualquier derecho de prelación ${ }^{24}$. La villa, por el contrario, aducía «que el alle. y Jurados de la dha. Villa de Bera de tiempo antiguo e ynmemorial a esta parte estan en quieta y pacifica posesion de prefirir a todos los demas Vecinos de la dha. Villa en los concursos publicos (...) y esto mismo se deve observar y guardar en todos y qualesquiera actos que concurrieren los dhos. Jurados y su alle. en forma y Represenon. de Comunidad asi dentro como fuera de la yglesia» ${ }^{25}$.

La segunda sentencia, fechada en 21 de julio de 1672, anulaba la primera y admitía la precedencia del alcalde y de los regidores en actos eclesiales y procesiones y la de los ancianos y excargohabientes en el acto de tomar la paz y en las procesiones ${ }^{26}$.

\footnotetext{
${ }^{21}$ Ibidem, fol. $111 \mathrm{v}$.

22 Ibidem, fol. 147.

Ibidem, fol. 155.

Ibidem, fol. 164

Ibidem, fol. 168-168v.

Ibidem, fol. 223.
} 
Seguidamente, la reacción partió ahora de Yriarte y de los demás quejantes, a los que se les unía Diego de Hualde, el dueño de la casa de Garmendia mayor. En su discurso, además de repetir razonamientos ya esgrimidos, justificaban históricamente - partiendo del argumento de «los primeros pobladores»- la existencia de preeminencias en el seno de la población: «Primte. que en la costumbre que avido en la Yglessia parroquial de la dha. Villa de bera y la que siempre se a observado y observa y es que los asientos y bancos que ay en ella son de particulares y ocupan aquellos prefiriendo los unos a los otros conforme la antiguedad de sus cassas que se regulo por los primeros pobladores y estimacion que adquirieron en los repetidos servicios de los Reyes $Y$ en todo lo que tocava a la conveniencia de la dha. Va. y los que despues aca an benido a poblar a ella por no tener dro. de sentarse en los dhos. escaños respecto de estar ocupados y ser pribatibos de los que ocupan aquellos se acomodan en los suelos» ${ }^{27}$. Como prueba parcial de todo ello, se adjuntaba la copia de un auto municipal de 1561 en el que se otorgaba a los dueños de la casa de Garmendia mayor el derecho a ocupar los primeros lugares, después del alcalde en las ceremonias eclesiales ${ }^{28}$.

En fin, la tercera y última sentencia - fallada en octubre de 1772 fue favorable a los quejantes, aunque no absolutamente. Si por un lado se prohibía a los regidores situarse junto al alcalde, se reconocía el derecho de precedencia a sólo nueve de los doce quejantes, dejando fuera a Miguel de Yriarte ${ }^{29}$.

El acto final de las tensiones entre la villa de Vera e Yriarte ocurrió en 1688 con la consignación en favor de él y de un tal Esteban de Sanjuanena de un censo de 4.247 ducados por parte de los vecinos ${ }^{30}$. En realidad, ese préstamo encubría un traspaso ya que con esa cantidad los vecinos adquirían ese mismo año al señor de Alzate «todos los derechos anejos al dicho Palacio de Alzate, incluso el del patronato de la Yglesia Parroquial (...) y el de la presentación del Rector y beneficiados para la misma, como el de preferencias y sepulturas de dicha Yglesia” ${ }^{31}$.

\footnotetext{
Ibidem, fol. 250.

Ibidem, fol. $250 \mathrm{v}-251$.

lbidem, fol. 305.

ANV, Leg. 18,1692, doc. 17.

Archivo de Itzea, "Extractos de la antigüedad y nobleza de la villa de Vera».
} 
Curiosamente, años después se reprodujo la actitud de Yriarte en la de un indiano enriquecido: en 1707 Santiago de Echenique ofrecía a la villa la luición de ese crédito de 4.247 ducados — que había dimanado ya cuantiosos réditos impagados- a cambio de «que se le diesen los montes Jarales y trasmochos pa. valerse de ellos por tiempo de 60 años, $y$ las precedencias de dentro y fuera de la Ygla. despues del Alcalde, cediendole las que en otros Tiempos tubo la Casa de Alzate». Al igual que sucedió con Yriarte, también en esta ocasión los vecinos rechazarán esas pretensiones. Con todo, de la repercusión entre la población de la localidad de la oferta de Echenique pueden dar idea las «grandes inquitudes y escandalos" que suscitó, así como el hecho de que pidiera el Real Consejo que se nombrara "comisario y Alguacil que concurriesen a la Junta» del Concejo "pa. proceder a recivir Ynforman. y prender o asignar los culpados si en ella huviese inquietudes o vias de hecho» ${ }^{32}$.

\section{LOS CONFLICTOS ENTRE LOS ANDUEZA Y EL VALLE DE ARAIZ}

De forma similar al caso anterior, las diferencias mantenidas entre el señor de Andueza y el valle de Araiz además de en tensiones bien patentes, se tradujeron en episodios de manifiesta dureza.

Los Andueza colaboraron, prestando notorios servicios, con las tropas castellanas en la guerra de anexión de Navarra. También se hallaron presentes en empresas posteriores en favor de la corona a lo largo de todo el resto del siglo y del siguiente. Tuvieron asiento en Cortes y uno de ellos fue nombrado Tesorero del reino en $1594^{33}$.

La primera referencia a un enfrentamiento entre las dos partes la proporciona Idoate y aparece también consignada en un proceso de 1618 por el que los jurados, los vecinos y el concejo de Arriba -localidad enclavada en dicho valle - litigaban contra Pedro de Lodosa y Andueza con el fin de impedirle colocar su escudo y armas en su asiento parro-

32 «Proceso de Expte. de la va. de Bera que dio principio en el año de 1707 y finalizo del de 1734». AMV, Leg. separado, doc. 7.

33 F. IDOATE, El señorio de Sarria. Pamplona 1969, pp. 279-294. 
quial. En 1574 los de Arriba, cuando el de Andueza ordenó sustituir un banco por otro en la capilla mayor de la parroquia de Arriba, los vecinos "a manera de motín y conjuración» rompieron el banco y lo arrojaron al río. En el pleito subsiguiente, los vecinos acusaban a Andueza de excesos en el cargo de alcalde perpetuo, de quebrantamientos de las ordenanzas referidas a la caza, etcétera ${ }^{34}$. Por la sentencia los responsables del acto fueron castigados a azotes y a la reposición del escaño ${ }^{35}$.

Posteriormente, adelantándose en una quincena de años a Alzate, en 1595 Fermín de Lodosa y Andueza desataba un proceso de brujería de importantes dimensiones. Pruebas de su responsabilidad son la circunstancia de que el auto que dio origen al proceso esté fechado en el propio palacio de Andueza y la de que en él el propio palaciano dijera "que es a su noticia que en la dicha valle hay muchas personas que estan lisiadas y que son brujas". De las 17 personas que fueron encarceladas en Pamplona, varias de ellas fallecieron en prisión ${ }^{35}$ bis.

Con estos antecedentes, son lógicos los afanes reivindicativos vecinales. En el pleito ya citado de 1618 la postura de los vecinos de Arriba niega de raíz cualquier posibilidad de que Andueza coloque sus armas en asiento alguno ya que además de no poseer patronazgo alguno sobre la iglesia, antiguamente los del palacio ni siquiera poseían un escaño particular en la iglesia ${ }^{36}$.

De otro lado, en 1620 el valle se opondrá a la concesión de alcaldía perpetua al hijo de don Pedro de Lodosa y Andueza. De acuerdo con la exposición del abogado del valle, fue éste el que nombró a don Pedro y a su padre como alcaldes vitalicios «con expressa condicion despues de sus dias quedase el dro. de ella a la dicha valle». Además, los nombramientos fueron a requerimiento de ellos: Pedro de Lodosa, por ejemplo, "andubo en persona por todas las cassas de la dicha valle pidiendo a todos los vezinos de uno en uno le hicieran mrd. de la dicha vara para

34 Ibidem, fol. 285

35 «Proceso de los jurados, vecinos y concejo del lugar de Arriba contra dn. Pedro de Lodosa y Andueza del consexo de S. Magd. y su tesorero gral. de este reino sobre inivicion para que no ponga en el escaño en que se sienta en la Parroquial de dho. lugar, esculpido el escudo y armas de su varonia, sobre que recombiene poderlo hazer, como quien prefiere en los actos de dha. Yglesia dueño del palacio de dho. lugar e Ydalgo". AGN, Procesos, Solano, Sentenciados, 1618, fajo 1, carp. 22, fol. 11.

35 bis F. IDOATE, La brujeria en Navarra y sus documentos. Pamplona 1977, pp. 131-143.

36 "Proceso de los jurados, vecinos y concejo del lugar de Arriba...", fol. 57 
durante su vida asegurandolos $\mathrm{q}$. Ios tenia en buena paz y justicia sin azer agravio alguno a niguno de ellos y la valle no quisso venir en que se hiziera nombramto. de Alle. en el dicho don pedro y por haverse puesto de por medio algunos sacerdotes y gente principal pidiendo muy encarecidamente hiziessen el dicho nombramiento y por mendio de ellos le nombraron". Por otra parte, el comportamiento de los Andueza no había sido el idóneo como para que se transmitiera el cargo al vástago más joven: si el padre de don Pedro había hecho intentos -fracasados al final- de nombrar él mismo a los almirantes del valle, don Pedro los coaccionaba, encarcelaba arbitrariamente a quienes se le oponían, se jactaba de recibir algunos productos por pechas - siendo que «todos los vezinos de la valle de Arayz son hijosdalgo en propiedad y possesion sin que devan pecha ni servidumbre alguna»- y ocasionaba pleitos por falsas pretensiones de preeminencias en las iglesias haciendo gastar a los vecinos mucho dinero ${ }^{37}$. Ante todo esto, el procurador de los Andueza se limitaba prácticamente a señalar los méritos militares del linaje y de sus defendidos y a que desde hacía más de doscientos años habían sido alcaldes perpetuos del valle, habiéndolo desempeñado «con toda satisfacion rectitud y limpieça» ${ }^{38}$.

Con posterioridad, en 1628 ambas partes protagonizaron otro proceso, por desgracia perdido. Según reza el inventario, obedecía a que los jurados del valle habían nombrado almirantes sin apelar a la intervención del palaciano ${ }^{30}$. Con todo, la derrota de los Andueza estaba bien cercana: en 1630 el valle compraba del monarca la jurisdicción civil baja y mediana por 500 ducados y en 1665 obtenía por 300 ducados la gracia de que la jurisdicción criminal no se enajenara de la corona ${ }^{40}$.

37 «Proceso del valle de Araiz contra el sr. fiscal, el capitán dn. Pedro Lodosa y Andueza del consexo de S. Magd. su tesorero Gral. de este reino y dn. Joseph su hixo sobre que no se le de uso a la real zedula, obtenida por dho. Andueza de Alcalde perpetuo de dho. valle por no poderlo ser sin consentimto. de este». AGN, Procesos, Solano, Pendientes, Leg. 2614, 1620, fajo 2, carp. 14, fol. 8-10.

38 Ibidem, fol. 20-23.

39 AGN, Inventarios del Real Consejo, t. 13, fol. 107v.

40 Yanglas y MiRANDA, Diccionario de antigüledades, voz Araiz. 


\section{LOS CONFLICTOS ENTRE LE LUGAR DE EZCURRA Y SUS PALACIANOS}

Si por lo general las ofensivas vecinales antinobiliarias consiguieron casi siempre de una manera o de otra la victoria, el lugar de Ezcurra constituye una notable excepción puesto que las concesiones jurisdiccionales logradas por el representante del palacio colocaron a aquél en una posición no muy lejana de la señorialización.

El primer proceso que examinaré se inicia en 1627 y lo que se discute en él es la respuesta a la petición de don Juan de Ezcurra de otorgamiento de la jurisdicción civil del lugar. Reunidos en batzarre o asamblea concejil el 24 de junio de 1627, los vecinos acordaban pleitear contra Juan de Ezcurra en vista de que pretendía "hacerse alcalde del dho. lugar de ezcurra» ${ }^{41}$.

En la exposición del procurador de don Juan de Ezcurra se hace constar que éste es dueño del palacio del lugar, tiene asiento en Cortes y recibe los diezmos parroquiales y nombra al vicario por ser el único patrono de la parroquia de la localidad. Además, se narran los servicios realizados a la monarquía por los miembros del linaje: por Martín Sanz de Ezcurra, abuelo del litigante, en la época de la anexión (por los que recibió 10.000 maravedís de acostamiento) y posteriormente, por Juan de Ezcurra, padre, que fue merino de la merindad de Sangüesa y capitán de los valles de Santesteban de Lerín y en las Basaburúas; y por el mismo querellante que desde hace una veintena de años es capitán de los mismos valles. La petición de alcaldía en lo civil se justifica por el coste económico del trámite judicial en Pamplona - de los que resulta "que en pleitos de muy poca consideración gastan (los vecinos) seys y ocho veces mas de lo que monta el interes prinl.»- y por la actuación «por no aver justicia» de «muchos Ladrones y quatreros Gitanos y franceses que urtan y roban qualquier Ganado". Según el mismo procurador, la venta perpetua de dicha jurisdicción civil «no vale treçientos ducados

41 “Proceso de Dn. Juan de Ezcurra, cuios son los Palacios del Lugar de Ezcurra contra los sres. Fiscal y Patrimonial y los Jurados, vecinos y concejo de dho. lugar de Ezcurra sobre que se informe a S. M. en virtud de su real cedula sobre la merced que pide el demandte. para si y sus subzesores en su casa y Palacio del Titulo y Jurisdiccion a perpetuo de Alle. de dho. Lugar en lo cibil». AGN, Procesos, Arrastia, Pendientes, Leg. 511, 1628 , fajo 1 , carp. 24 , fol. $173-173 \mathrm{v}$. 
ni se allara quien Los diese sin mi parte por la comodidad que tiene de tener su cassa en el dho. lugar" ${ }^{42}$.

Por su parte, el fiscal destacaba tres circunstancias presentes y futuras respecto a la petición del palaciano. Primeramente, el gobierno del lugar por medio de «dos jurados y otros oficiales que cuydan de los proprios y rentas» ha tenido hasta al presente "tan buenos efectos que ni el dho. Lugar tiene tomado a censo sobre si solo un real ni los particulares sobre sus aciendas tampoco" y asimismo "en materia de quietud y comformidad an bibido y biben tan sin pleitos y diferencias que de veynte treynta cuarenta y mas años a esta parte no se allara que aya abido en vra. corte pleito civil entre los dhos. vezinos, porque entre ellos se conponen si tienen alguna diferencia amigablemente por escusar la costa y odios». En segundo lugar, si «se mudase la forma del govierno (...) se sintirian muchos yncombenientes en la administracion de la justicia» pues don Juan de Ezcurra "yntentaria pleito sobre qualquier niñeria y aunque el dho. alle. les administrase Justicia con toda entereça abiendose empeñado una Bez en el pleito le seguirian porfiadamente en las ynstancias de corte y consejo con grande costa y perdida de sus aciendas por no dejarse vencer de la prima. sentencia del dho. alle.». En tercer lugar, la concesión supondría establecer de facto un casi señorío: "Yttem que siendo el dho. Don Juan Patron de la Parroquial del dho. Lugar y llebando las decimas de ella y teniendo otros muchos honores y preminencias por dueño del dho. palacio y siendo respecto de la calidad de su persona tan ynferiores a el todos los vezinos del dho. Lugar y estandole tan subordinados por las razones susodhas. si se añadiese de nuebo a las preeminencias de su casa la jurisdicion de all. perpetuo seria tanto como ser señor absoluto del dho. lugar en lo espiritual y temporal teniendo tan rendidos a todos los vezinos del que en ninguna ocasion abria quien se opusiese a sus yntentos". Además, respecto al precio de venta, «la calidad de alle. perpetuo del dho. Lugar es de tan grande autoridad y probecho que su precio de venta no podia ser menor de 50.000 ducados». Para finalizar, recordaba que la legislación del reino iba en contra de la presencia de alcaldes perpetuos «por los ynconbinientes que se an esperimentado en los valles o lugares donde los a avido" ${ }^{43}$.

Por su parte, el procurador de los vecinos, a la vez que hacía suyos los argumentos del fiscal, destacaba otros. De esta forma consideraba

\footnotetext{
42 Ibidem, fol. 176-177v.

43 Ibidem, fol. 181-182.
} 
que las mercedes y acostamientos recibidos por los Ezcurra eran ya premio suficiente y también hacía hincapié en la hidalguía de los vecinos no sujetos a servidumbre alguna: "Yttem que el dicho lugar y sus vecinos decendientes del es, an sido y son hijos dalgo gente Honrrada y bien nacida (...) y por tales an sido y son tenidos sin que se aya visto oydo ni entendido cosa en contrario ni que aya devido ni deban ni paguen pecha ni otra servidumbre». Ya la jurisprudencia había ratificado esa falta de servidumbres ${ }^{44}$.

En una exposición posterior, el procurador de Ezcurra recordaba que anteriormente había habido sólo un pleito entre las partes, sobre el nombramiento de una serora. En él perdieron los vecinos y además se resolvió la obligación de diezmar la leche. Subrayaba asimismo la labor de protección de Ezcurra sobre los vecinos - que «siempre los a amparado y defendido" - y destaca la dificultad de los más pobres por defender sus haciendas al no poder soportar los gastos procesales en Pamplona. Por último, afirmaba que en 1297 se le había adjudicado al palacio «la villa y terminos de Ezcurra», haciéndose «relaon. de que avia collaços» ${ }^{45}$.

Ante esto, los vecinos aducen la mención de hidalguía colectiva que aparece en el libro de fuegos de 1427, así como el hecho de que paguen los cuarteles y alcabalas a través del molino concejil y de que la recepción de productos por parte del palaciano se deba sólo a obligaciones decimales. A la vez, niega la existencia de pleitos intercomunitarios, afirmando la solidaridad con los pobres del lugar por parte de los demás miembros y cuestionan la autenticidad de la sentencia de $1297^{46}$.

Los testigos presentados por el fiscal -que van desde la regata del Bidasoa hasta el valle de Larraun - hablan, algunos de ellos con claros tonos antipalacianos, de las alcaldías perpetuas que hubo en la zona - Ytúrbide en Baztán, Subiçar en Sumbilla, Vertiz en Bertizarana, Viguria en Imoz y Basaburua Mayor-, todas ellas contestadas por los vecinos. El fiscal real y el procurador de la villa denunciaron, en fin, la parcialidad interesada o amistosa de muchos de los testigos presentados por don Juan de Ezcurra ${ }^{47}$.

\footnotetext{
Ibidem, fol. 184-186.

Ibidem, fol. 195-196v

Ibidem, fol. 203-204.

7 Ibidem, fol. 392-393.
} 
A pesar de todos sus esfuerzos, los vecinos de Ezcurra no pudieron evitar en 1630 la concesión real a perpetuidad en favor del palacio por 1.500 ducados de la jurisdicción civil baja y mediana de la localidad. Esa concesión llevaba aparejada la elección de alcalde de entre un trío de personas que presentaría el concejo ${ }^{48}$.

Posteriormente, en 1688 otro proceso se dirimió ante el mismo Tribunal del Real Consejo entre el marqués de Santacara, dueño del palacio de Ezcurra, y los vecinos del lugar sobre si éstos debían o no titular a aquel "señor de Ezcurra". Según afirmaban los vecinos a finales de 1687, tras haber escrito al marqués con la terna de candidatos para alcalde del año siguiente "con todo buen tratamo. dandole al dho. marques todos los titulos que por esta parte le tocan", éste había excusado hacer la elección «a menos que el Lugar le Reconozca y le yntitule por su señor ${ }^{49}$.

En otro bazarre de 13 de enero de 1688 los vecinos resolvían llegar a un convenio con el marqués debido a que «aunque el dho. sr. Marques no tiene dominio de señorio en el dho. lugar mas de ser señor de la Jurisdizon. (...) y Abadia de su Yglesia Parroquial y que solo por esto tiene mucha autoridad y se le debe tener respecto particular (...) y pr. evitar pleitos e yncombinientes y vibir en paz y quietud y escusar litigios ygastos" ${ }^{50}$.

El convenio se firmaba en Pamplona el 8 de febrero del mismo año y consistía en tres puntos. Por el primero, los vecinos se comprometían a otorgar al marqués y a sus sucesores como dueños del palacio de Ezcurra y de la jurisdicción civil «el titulo y tratamiento de señor de la dha. villa (...) durante tubieren la Jurisdizion de la dha. villa y no mas $y$ que solo por razon de ella se le da el tratamiento de señor y no por otra causa respecto de que por las sentencias que quedan referidas esta declarado no poderse yntitular señor de la dha. villa". Por el segundo, el marqués renunciaba al derecho - de poco provecho para él- de recepción de la leche el día de la víspera de San Pedro. Por el tercero, el

48 AGN, Libro 23 de Mercedes Reales, fol. 97-98.

49 «Proceso de el Marques de Santacara, Vizconde de Castejon contra el señor Fiscal y el Lugar de Ezcurra sobre si a dho. Marques se le ha de titular señor de Ezcurra en las cartas que se le escribiera por dho. Lugar y demas instrumentos que hiziere en que se ofreciera ablar con el, y otras cosas». AGN, Procesos, Mendibil, Pendientes, Leg. 456, 1688 , fajo único, carp. 2 , fol. 3.

so lbidem, fol. 8. 
marqués confesaba que los vecinos de Ezcurra eran «libres de toda pecha servidumbre y obligazon. y que solamente an pagado y pagan los diezmos de sus frutos a su señoria» ${ }^{51}$.

Sin embargo, justo una semana más tarde, los vecinos revocaban el poder otorgado a su representante en la firma del convenio por considerar que por éste resultaban "laxsos y engañados y gravemente perjudicados» al haberse excedido el apoderado en sus atribuciones ${ }^{52}$.

Ya en el pleito propiamente dicho, el procurador del marqués sostenía que la posesión de la jurisdicción conllevaba el señorio ya que tal cosa podía inferirse de la sentencia de un proceso que el bisabuelo de su representado mantuvo con la villa de Santacara en $1608{ }^{53}$.

A esa pretensión, el procurador de la villa oponía el carácter de realengo de ésta y negaba la existencia en Ezcurra de cualquier tipo de vasallaje que, por lo visto, sí pudiera existir en Santacara ${ }^{54}$.

A su vez, la respuesta de la otra parte afirmaba la compatibilidad del tratamiento de "señor" con el carácter de realengo de la villa y con el hecho de que el marqués sólo disfrutara de la jurisdicción civil baja y mediana -esto es, sin la criminal- por ser una regalía. Asimismo, presentaba documentos que probaban el empleo por parte de los vecinos del título de "señor ${ }^{55}$.

En su réplica, el abogado de los vecinos se centró en el poco crédito de esa documentación ${ }^{56}$.

El último pleito entre una y otra parte que he localizado hace referencia a posibles ocultaciones en los pagos decimales por parte de los vecinos. Surgido por la queja vecinal de una deficiente atención eclesiástica, en un lugar del documento el procurador del palaciano indica cómo "por la ausencia de los Patronos e Ygnorancia de estos» los vecinos no diezmaban ni mijo ni alubia ${ }^{57}$. La defensa de los vecinos alegará, ade-

\footnotetext{
Ibidem, fol. 9-10v.

Ibidem, fol. $74 \mathrm{v}$.

lbidem, fol. 83 .

Ibidem, fol. $87-87 \mathrm{v}$.

lbidem, fol. 146 .

Ibidem, fol. 148

ADP, Ollo, 1588-6, fol. 46.
} 
más de la escasez de la cosecha de esos productos, que nunca ha habido práctica dezmatoria de ellos ${ }^{58}$.

\section{CONFLICTOS EN OTROS VALLES}

Generados en otros valles y localidades de la Montaña navarra presento varios pleitos sueltos que repiten en su individualidad moldes vistos más arriba.

El primero de ellos es el que mantuvieron don Ramiro de Eraso y el valle de Araquil por la alcaldía perpetua de aquél. Esta alcaldía fue, junto con las ya contempladas de Araiz y de Ezcurra, la de más larga perduración en el entorno geográfico objeto de nuestro análisis. Procedía desde los tiempos del bisabuelo del litigante, desde 1467 más exactamente, y desde entonces se había transmitido hereditariamente ${ }^{59}$. En la exposición del procurador de don Ramiro de Eraso se solicita la concesión de alcaldía perpetua para el hijo de éste, describiéndose los méritos militares de los antecesores del linaje. Aún cuando, según él, de esa concesión «no puede resultar inconveniente sino mayor servio. a su mag.", no deja de reconocer que en 1579 vecinos del valle pleitearon por conseguir que la alcaldía fuera anual. Entonces la sentencia dictaminó que al morir don Ramiro se instauraría alcaldía anual ${ }^{60}$.

Según el fiscal en los Eraso no había habido filiación legítima. Además, siempre se consideraron «hombres llanos y ordinarios sin que se entendiese hazer bentaja a las demás personas y vezos. de los lugares donde an bivido" y sus palacios "no an sido ni son palacios sino (casas) hordinarias como las demas». Tampoco había acudido a Cortes «ni menos al braço de los caballeros». Por otro lado, además de rebajar los

58 Ibidem, fol. 117

59 «Proceso de Remiro de Eraso Alcalde perpetuo de la valle de Araquil cuyos son los palacios de Echeberri e Ychurieta contra el fiscal y patrimonial de su Magestad y la dicha valle de Araquil sobre zedula de ynformacion en razon de la merced que el dicho Eraso suplica se le aga por su Magd. de que se pase el dho. oficio de Alcalde perpetuo en dn. Carlos de Eraso su hixo". AGN, Procesos, Gayarre, Pendientes, Leg. 3114, 1609, fajo 1 , carp. 10, fol. 2.

60 Ibidem, fol. 3-5. 
méritos militares de los Eraso, destaca el «mucho aprobechamiento» de la alcaldía perpetua y el hecho comprobado «que quando los oficios son perpetuos suelen hazer muchas bejaciones y quedan con grande daño las partes lo que no sera siendo añales o trienales porque se pidira el castigo despues de pasado el tiempo de alle. y en ser perpetuo en ninguna manera se pide castigo por el temor grande que las partes quexantes tienen de que los amolesten como tales alles." ${ }^{61}$.

Por su parte, el valle de Araquil recordaba las sentencias de 1586 y 1588 por las que "esta mandado que despues de los dias del dicho ramiro de erasso el dicho oficio de alle. sea aynal y no perpetuo" y denunciaba como falsas las declaraciones de los testigos presentados por Eraso en orden a sus méritos militares y demás cosas ${ }^{62}$.

En el caso de la villa de Echalar y los del palacio de Gaztelu, el objeto de la querella fue el molino harinero ya que en 1605 los vecinos determinaron la construcción de uno nuevo - "con fin de aumentar los propios y rentas» de la villa - sobre el mismo río en que se asentaba el del palacio, hasta entonces el único existente. Calculado su grado de perjuicio, Martín de Gaztelu, dueño a la sazón del palacio, había decidido su venta. Ante esta decisión los vecinos pensaron como más útil y menos perjudicial para los Gaztelu - «con quienes siempre an conserbado mucha amistad"- adquirir su molino en vez de emprender la construcción de uno nuevo. La estimación del molino y de las heredades anejas se cifraba en 1.663 ducados, 1.500 de ellos por el molino. Esos 1.500 ducados se pagarían en forma de censo a Martín de Gaztelu con un redituado anual de 90 ducados ${ }^{63}$.

No obstante, contra este principio de acuerdo se constituyó como parte contraria Brígida de Echevarría, cuyos hijos con el tiempo deberían de heredar los bienes correspondientes al solar. Sus razones no se refieren para nada a posibles facultades de los Gaztelu para impedir la construcción del nuevo molino, sino sólo a que el molino rentaba de por sí

61 Ibidem, fol. 57-58.

62 Ibidem, fol. 65.

63 «Proceso de la villa de Echalar y martin de Gaztelu, cuio es el palacio de dha. villa contra los testamentarios de doña Catalina Gaztelu, viuda de Martin Oteiza, recividor de Sanguesa, y Brigida de Echevarria, viuda de Juan de Gaztelu, tutora de sus ixos, vecina de la villa de Lesaca, sobre permiso para comprar dha. villa, de dho. martin de Gaztelu, un molino arinero». AGN, Procesos, Solano, Pendientes, Leg. 2580, 1605, fajo 3, carp. 7, fol. 3-4. 
«mas de dozientos ducados cada un año» ${ }^{64}$. De esta forma, en 1609 ella misma alegaba una sentencia por la que se veía obligada a entregar su molino a la villa antes de tres meses a cambio de 1.700 ducados, de los que 1.500 constituían una imposición censal a $6 \% .^{65}$ Con todo, el pleito finalizaría hacia 1610 con un arreglo entre ambas partes por las que se interesaban a medias tanto en el molino del palacio como en el de nueva edificación ${ }^{66}$.

Para finalizar, el proceso de Pedro Reparaz y Oteiza, palaciano de Oteiza en Bertizarana, contra diversos vecinos de ese valle repite esquemas ya vistos en Vera. Según el procurador de Reparaz, éste poseía una ermita - llamada de San Salvador- en la que los del valle solían efectuar paradas en sus procesiones y además iba el primero, después del alcalde, en la procesión de letanías, al igual que lo habían hecho los palacianos anteriores. Sin embargo, el día 8 de mayo de 1684 al regresar la procesión desde Sumbilla, cuando Reparaz iba en la posición para él acostumbrada, varias personas le impidieron proseguir «diziendo que querian que despues del dho. Alcalde fuese su theniente ${ }^{67}$.

En la versión del abogado de los acusados, se rebatía duramente cualquier presunción de derechos por parte del palaciano. Primeramente, aunque la basílica de San Salvador de Oteiza se sitúa en términos de Oteiza y jurisdicción de Bertizarana, la procesión hacia ella es por "voluntad libre porque an podido y pueden ir a otra Yglesia o hermita como quisieren elegir». En segundo lugar, el palacio no pertenece eclesiásticamente al valle de tal forma que en sus iglesias no tienen ningún asiento ni sepultura. Es sólo en su carácter de extranjeros y «por urbanidad y por agasajarlos" - tal y como es tradición en el valle y en otros lugares del contorno- que han admitido algunas veces a los del palacio en las procesiones después del alcalde. Además, nunca en Bertizarana

64 Ibidem, fol. 7.

65 «Proceso de Brígida Echevarria, viuda de Juan Gaztelu, madre y tutora de sus hijos, vezina de la villa de Lesaca contra la villa de Echalar sobre Apelación y Nulidad de una sentencia arbitraria en razón a la construcción de un nuebo molino». AGN, Procesos, Mendibil, Pendientes, Leg. 331, 1609, fajo 1, carp. 15, fol. 3-3v.

66 AGN, Protocolos notariales, not. J. F. Echalar Berroeta, 1810, Leg. 37, doc. 54.

67 «Proceso de Pedro Reparaz y Oteiza cuyo es el Palacio de Oteiza contra Oxer de Alzugarai Alle. que fue del valle de Bertizarana, Juan Miguel de Hualde Jurado que fue de Narvarte, Juan de Albirena vezo. de Legasa y Domingo de Yturralde vezo. de Oyeregui criminal sobre haber perturbado a dho. Palaciano segun este supone de la posesion de $\mathrm{Yr}$ inmediato al Alle. en la procesion de Letanias». AGN, Procesos, Mendibil, Pendientes, Leg. 455,1687 , fajo único, carp. 2 , fol. 1-2v. 
habian habido preeminencias en las iglesias por parte de palaciano alguno. Así en Narvarte, al palaciano de Reparacea le prefieren "ocho y mas vezos. en los dhos. actos de sentarsse ofrezer y en dhas. procesiones». Incluso en Santesteban, a cuya feligresía pertenece Oteiza, los del palacio no han tenido nunca ninguna prelación. Respecto a los hechos acaecidos en la procesión, el motivo primario residía en el intento de Reparaz en una procesión anterior de adelantarse al alcalde "con el pretexto de pedir tabaco a los sazerdotes que yban y hazer conbersacion con ellos». En vista de ello "y porque aldelante no sucediesse lo propio delibero el dho. valle el que ynmediato al dho. Alcalde fuese su teniente en las procesiones». En este contexto, en la versión de los acusados, fue el quejante quien reaccionó bruscamente ante las recriminaciones del alcalde, dando "diferentes empellones" al teniente. Asimismo, respondió el quejante "con mucha colera" a Juan de Albirena y Domingo de Yturralde quienes le dijeron "porque drecho pretendia aquella prelacion" que "hera mas que ellos con dos dedos de ventaja", a lo que no se produjo ninguna acción violenta «por la irreberencia que se podia seguir iendo en la dha. procesion» ${ }^{68}$.

68 Ibidem, fol. 40-42v. 